\title{
Risk of bleeding associated with nonsteroidal anti-inflammatory drug use in patients exposed to antithrombotic therapy: a case-crossover study
}

Morgane Paternoster, $\mathrm{MD}^{1}$; Olivier Steichen, $\mathrm{MD}, \mathrm{PhD}^{2,3}$; Maryse Lapeyre-Mestre, $\mathrm{MD}, \mathrm{PhD}^{4}$; Thierry Blanchon, MD, PhD ${ }^{1}$; Louise Rossignol, MD, PhD ${ }^{1,5}$; Ana-Maria Vilcu, $\mathrm{PhD}^{1}$; Titouan Launay, $\mathrm{MSc}^{1}$; Marianne Sarazin, MD, PhD; Haleh Bagheri, MD, $\mathrm{PhD}^{4}$; Cécile Conte, $\mathrm{PhD}$, PharmD ; Clément Turbelin, $\mathrm{MD}, \mathrm{PhD}^{1}$; Thomas Hanslik, MD, $\mathrm{PhD}^{1,6,7}$; Cécile Souty, $\mathrm{PhD}^{1}$

1. Sorbonne Université, INSERM, Institut Pierre Louis d'épidémiologie et de Santé publique, Paris, France

2. Sorbonne Université, INSERM, Université Paris 13, Laboratoire d'informatique médicale et d'ingénierie des connaissances en e-santé, LIMICS, Paris, France

3. Assistance Publique - Hôpitaux de Paris (APHP), hôpital Tenon, Service de Médecine Interne, Paris, France

4. INSERM, Université de Toulouse (LEASP UMR 1027), Service de Pharmacologie médicale et clinique, CIC 1436, Centre Hospitalo-Universitaire de Toulouse (CHU Toulouse), Toulouse, France

5. Université de Paris, Département de Médecine Générale, Paris, France

6. Université de Versailles Saint-Quentin-en-Yvelines, UVSQ, UFR de Médecine, Versailles, France

7. Assistance Publique - Hôpitaux de Paris (APHP), hôpital Ambroise Paré, Service de Médecine Interne, Boulogne Billancourt, France

\section{Corresponding author}

Morgane Paternoster

IPLESP UMRS 1136

27 rue Chaligny, 75571 Paris Cedex 12 France

morganepat@gmail.com ID ORCID https://orcid.org/0000-0002-3534-4538 


\section{Acknowledgement}

We thank the French National Agency for Medicines and Health Products Safety (ANSM) for their financial support.

\section{Funding information}

This project has received funding from the French National Agency for Medicines and Health Products Safety (ANSM, \#AAP-2017-059). This publication represents the views of the authors and does not necessarily represent the opinion of the ANSM.

\section{Conflict of Interest}

The authors declared no competing interests for this work.

\section{Data availability}

The data that support the findings of this study are available from third party (data owner). Restrictions apply to the availability of these data, which were used under license for this study. Data are available from the authors with the permission of third party.

Word count: 3488

Table count: 5

Figure count: 2

Number of references: 32

Supplementary online material: Yes 


\section{Abstract}

Concomitant nonsteroidal anti-inflammatory drug (NSAIDs) and antithrombotic drug use is associated with an increased risk of bleeding, mainly gastrointestinal.

The goal of this study was to quantify the transient increase in the risk of hospitalization for bleeding associated with NSAID use in patients treated with antiplatelet agents or anticoagulants.

We performed an unidirectional case-crossover study using the EGB (Échantillon généraliste de bénéficiaires), a permanent random sample of the French nationwide health database. Patients receiving antithrombotic therapy and hospitalized for bleeding between 2009 and 2017 were included. We compared their NSAID exposure during a 15-day hazard window immediately prior to hospital admission to three earlier 15-day control windows. The risk of hospitalization for bleeding associated with the recent use of NSAIDs was estimated using conditional logistic regression to estimate odds ratios.

During the study period, 33 patients treated with anticoagulants and 253 treated with antiplatelet agents received NSAIDs and were included in the case-crossover analysis. We found an increased risk of hospitalization for gastrointestinal bleeding after exposure to NSAIDs with an adjusted OR of 3.59 $(95 \% \mathrm{Cl}, 1.58 ; 8.17)$ in patients receiving anticoagulant therapy and $1.44(95 \% \mathrm{Cl}, 1.07 ; 1.94)$ in patients receiving antiplatelet therapy. The risk of non-gastrointestinal bleeding was also increased after exposure to NSAIDs with an adjusted OR of $2.72(95 \% \mathrm{Cl}, 1.23 ; 6.04)$ in patients exposed to anticoagulant therapy.

The risk of gastrointestinal and non-gastrointestinal bleeding increases after NSAID use in patients treated with anticoagulants, while the risk of gastrointestinal bleeding increases, but to a lesser extent in those treated with antiplatelets.

Keywords: Pharmacovigilance; drug safety; drug interactions; adverse drug reactions; nonsteroidal anti-inflammatory drugs (NSAIDs); antithrombotic 


\section{Introduction}

Antiplatelet agents and anticoagulants are antithrombotic drugs that are frequently prescribed for the prevention and treatment of cardiovascular diseases. Nonsteroidal anti-inflammatory drugs (NSAIDs), which have analgesic, anti-inflammatory and antipyretic properties, are often used to treat mild to moderate pain, in traumatology and rheumatology (osteoarthritis, rheumatism...). Thus, elderly people are very likely to take both treatments together, especially since several NSAIDs are available over-the-counter in pharmacies.

An estimated $5.3 \%$ to $69 \%$ of patients receiving antithrombotic treatment have concomitant exposure to NSAIDs ${ }^{1,2}$ while an antiplatelet agent was used by up to $22 \%$ of patients receiving NSAIDs for the treatment of osteoarthritis ${ }^{2,3}$. In France, $1.5 \%$ of the population was received NSAIDs and antiplatelet drugs simultaneously and $0.24 \%$ NSAIDs and oral anticoagulants in 2016, a trend that has been increasing in both populations in the past decade ${ }^{4}$. The association of these two drug classes increases the risk of bleeding, mainly gastrointestinal ${ }^{5,6}$.

The goal of this study was to quantify the risk of hospitalization for severe bleeding (gastrointestinal and non-gastrointestinal) in patients receiving antithrombotic therapy (antiplatelets or anticoagulants) and exposed to NSAIDs, based on pharmacy drug dispensing and hospital data from a French health insurance database.

\section{Methods}

\section{Ethics}

National Institute for Health and Medical Research (INSERM) agreement for the research protocol was given in 2017-11-15. Neither ethics committee authorization nor request to national commissions for individual data protection is required according to French law to access this kind of anonymous and restricted access database. Access to EGB is possible only through a secured connection to a specific 
server. Data are accessible online and are analyzed by the software SAS Enterprise Guide version 4.3 (Copyright @ 2006-2010, SAS Institute Inc., Cary, NC, USA).

\section{Data sources}

This study was performed using data from the EGB (Échantillon généraliste des bénéficiaires), a 1/97th random sample of the SNDS (Système National des Données de Santé), the French nationwide claims database which covers around $99 \%$ of the French population. The EGB database includes more than 700,000 individuals $^{7}$ and is representative of the French population for age, sex, geographical location, and healthcare use. The EGB provides anonymous sociodemographic and medical information since 2003, allowing longitudinal patient follow-up. It contains in depth data on hospital admissions and medications dispensed in community pharmacies transmitted for reimbursement.

Pharmacy dispensations of NSAIDs and antithrombotic drugs were identified according to the Anatomical, Therapeutic and Chemical (ATC) drug classification system and hospitalizations for bleeding were identified from the International Classification of diseases, Tenth Revision (ICD-10) diagnostic codes.

\section{Study design and study population}

We performed an unidirectional case-crossover analysis. In this self-controlled design each patient acts as his or her own control ${ }^{8}$, thus, the potential effects of time-invariant confounding factors, such as sex, genetic or socio-economic characteristics, chronic co-morbidities and long-term treatments, are controlled $^{8,9}$.

We included patients over 18 years old who had been continuously exposed to antithrombotic treatment and were hospitalized for severe bleeding between January 1, 2009 and December 31, 2017. Exposure to NSAIDs in these patients was compared between a hazard window ( 0 to 15 days before hospital admission) and three control windows (45 - 60 days, 90 - 105 days and 135 - 150 days before 
hospital admission) (Figure 1). We chose fifteen day-windows since the recommended duration for NSAID treatment is short. Each of these windows was separated by a thirty-day washout period, minimizing any relationship between the windows. Thus, the study period for each patient extended from the beginning of the third control window to hospital admission, for a total of 150 days (Figure 1).

\section{Hospitalizations for severe bleeding}

Severe bleeding included gastrointestinal, intracranial, urinary, gynecological, respiratory, joint, muscle, abdominal and post-procedural bleeding, anemia due to bleeding, and other unclassified hemorrhages. Hospitalizations were identified using ICD-10 codes registered as primary, secondary or related diagnosis. ICD-10 codes were selected from published studies and reviewed by an expert group (Table S1) ${ }^{10-12}$. We selected the first hospitalization for severe bleeding during the study period for each patient.

Our main analysis evaluated the risk of gastrointestinal bleeding. The secondary analyses evaluated hospitalizations for overt gastrointestinal bleeding (ulcers and gastritis with hemorrhage, hematemesis, melena, anal and rectal hemorrhage and unspecified gastrointestinal hemorrhage), and hospitalizations for occult gastrointestinal bleeding (ICD-10 code for iron deficiency anemia in men of all ages and women over 50 years of age). We also analyzed non-gastrointestinal bleeding and all bleeding combined.

\section{Exposure to antithrombotic therapy}

The antithrombotic therapy could be an anticoagulant (vitamin $\mathrm{K}$ antagonist (VKA) or direct oral anticoagulant (DOAC)), or an antiplatelet agent (acetylsalicylic acid at low dose (75 to $300 \mathrm{mg} /$ day) ${ }^{13}$, clopidogrel, prasugrel, ticagrelor or ticlopidine) (Table S2).

Patients included in the case crossover analysis were continuously exposed to antiplatelet agents or anticoagulants during the 150 days before their hospital admission for severe bleeding (Figure 1). Continuous exposure was defined by two criteria. Persistence was defined as a delay between the 
dispensation of two antiplatelet or anticoagulant prescriptions that did not exceed the estimated treatment duration plus a grace period of 30 days. We chose 30 days based on the packaging of antithrombotics in France and the median delay between two dispensations. Patients also met an adherence criterion so that the medication possession ratio (estimated as the total drug supply dispensed divided by the number of days of the period) had to be $\geq 0.8^{14}$. The treatment duration was estimated using the Defined Daily Dose (DDD) ${ }^{15}$.

\section{Exposure to NSAIDs}

Exposure to NSAIDs was investigated during the hazard and control windows. If NSAIDs were dispensed during one of the windows, the patient was considered to be exposed to NSAIDs.

\section{Statistical analysis}

We first evaluated the absolute risk of hospitalization for gastrointestinal bleeding associated with the exposure to NSAIDs in patient already taking an antithrombotic treatment. For this absolute risk analysis, we took into account hospitalisations from the start of NSAID treatment to 15 days after its end.

We then evaluated the risk increase of hospitalization for gastrointestinal bleeding associated to NSAIDs in patients on long term antithrombotic treatment. For this analysis, we used a case-crossover design. In this design, instead of using patients who were hospitalized for gastrointestinal bleeding as cases and matched subjects who weren't hospitalized for gastrointestinal bleeding as a controls, only patients hospitalized for gastrointestinal bleeding are included and exposure to NSAIDs is compared between a 15-day hazard window immediately preceding the hospitalization and three remote 15-day control windows (Figure 1). Moreover, only patients with discordant NSAID exposure between the hazard window and at least one control window are used to estimate the odds ratio (OR) with conditional logistic regression stratified on individuals. Separate analyses were performed for antiplatelet agents and anticoagulants. 
To prevent confounding by indication, we restricted our sample to patients with constant exposure to antithrombotic from the beginning of the observation period to hospital admission ${ }^{16}$. This also ensures that included patients complied with their antithrombotic therapy. Because of the short observation period (150 days), age and comorbidities were considered to be the same for all periods (control and risk). Analyses were adjusted for exposure to different medications between the hazard and control windows for drugs that could interfere with the risk of bleeding: proton pump inhibitors (PPI) or $\mathrm{H} 2$ antagonists, systemic or inhaled corticosteroids, anticoagulants in patients exposed to antiplatelet therapy and antiplatelet therapy in patients exposed to anticoagulant therapy. To determine whether the risk of bleeding was related to the use of NSAIDs or their indication, we also performed a case-crossover analysis using a negative control precipitating substance. We replaced NSAIDs with paracetamol, which has similar indications.

Moreover, sensitivity analyses were performed to assess the robustness of our estimates. We reduced the duration of the hazard and control windows from 15 days to 12,10 and 7 days, and the length of the grace period for the persistence criterion from 30 days to 15 days and 7 days.

All analyses were performed using the statistical software R version 3.6.

\section{Results}

\section{Risk of gastrointestinal bleeding}

From 2009 to 2017, in the EGB database, 8272 individuals have been exposed simultaneously to anticoagulant and NSAIDs. Among them, $74(0.89 \%)$ were hospitalized for gastrointestinal bleeding during or within 15 days after the end of the concomitant exposure. For antiplatelet agent and NSAIDs, 37718 individuals have been exposed to this association and $296(0.78 \%)$ were hospitalized for gastrointestinal bleeding during or within 15 days after the end of the concomitant exposure (Figure 2). Thirty-three patients with constant exposure to anticoagulants and 253 patients with constant exposure to antiplatelet were exposed to NSAIDs for at least one of the four 15-day windows preceding 
the hospitalization. The patients included in the case crossover analysis had "discordant" exposure to NSAIDs between the hazard and control windows, corresponding to 33 patients in the anticoagulant group and 250 patients in the antiplatelet group (Figure 2).

The main characteristics of the study population are described in Table 1. There were mostly men in both antithrombotic groups, and the median age was 74 (interquartile range (IQR) [69; 79]) in patients exposed to anticoagulant therapy and 78 (IQR $[68 ; 84])$ in patients exposed to antiplatelet therapy. Two-thirds of the patients exposed to anticoagulant therapy were dispensed at least one prescription of PPIs or $\mathrm{H} 2$ antagonists ( $n=22)$, as well as $71.2 \%$ of patients exposed to antiplatelet therapy $(n=178)$. A total of $66.7 \%$ of the 33 patients exposed to anticoagulant therapy were exposed to VKAs $(n=22)$, mainly fluindione $(n=20), 24.2 \%$ to direct oral anticoagulants (DOAC) $(n=8)$, mainly rivaroxaban $(n=6)$, and $9.1 \%$ to dual anticoagulant therapy, either to one DOAC and one VKA $(n=2)$ or two DOACs $(n=1)$ (Table S3). More than $80 \%$ of the patients exposed to antiplatelet agents, were receiving monotherapy ( $n=208)$, mainly acetylsalicylic acid $(n=168)$ and clopidogrel $(n=39)$, and $16.8 \%$ were receiving dual therapy with acetylsalicylic acid and clopidogrel $(n=42)$.

The median hospital stay in both antithrombotic groups was 7 days, and less than $5 \%$ of patients died during hospitalization (Table 1). Overt gastrointestinal bleeding represented $73 \%$ of hospitalizations in the anticoagulant group $(n=24)$ and $59 \%$ in the antiplatelet group $(n=148)$ (Table 2). In the anticoagulant group, these $73 \%$ were divided between $61 \%$ of hospitalizations for melena, hematemesis, anal/rectal hemorrhage or unspecified gastrointestinal hemorrhage $(n=20), 9 \%$ of hospitalizations for hemorrhagic gastrointestinal lesion (ulcer or gastritis type, $n=3$ ) and $3 \%$ of hospitalizations had two ICD-10 codes of overt gastrointestinal bleeding ( $n=1)$. In the antiplatelet group, this distribution of overt gastrointestinal bleeding was $48 \%(n=120), 8 \%(n=21)$ and $3 \%(n=7)$, respectively. Occult gastrointestinal bleeding represented $27 \%$ of hospitalizations in the anticoagulant group ( $n=9)$ and $41 \%$ of hospitalizations in the antiplatelet group ( $n=102)$. 
A total of $55 \%(n=18)$ of the patients exposed to anticoagulant therapy in the study were dispensed NSAIDs during the hazard window and $42 \%(n=104)$ of patients exposed to antiplatelet therapy (Table 1). More than $90 \%$ of the dispensations were non-selective NSAIDs in both antithrombotic group, while selective cyclooxygenase (COX)-2 inhibitors (celecoxib or etoricoxib) were prescribed in less than $10 \%$ of patients (Table 1). The median time from NSAID dispensation to hospitalization in patients exposed to this drug during the hazard window was 6.5 days (IQR $[2.5 ; 11.8]$ ) in patients exposed to anticoagulant therapy, and 8.0 days (IQR $[4 ; 11])$ in patients exposed to antiplatelet therapy.

Compared to NSAID use during the control windows, NSAID use during the hazard window was associated with an increased risk of overt or occult gastrointestinal bleeding in patients exposed to anticoagulant therapy (adjusted odds ratio (aOR), 3.59; $95 \% \mathrm{Cl}, 1.58 ; 8.17$ ) as well as to antiplatelet therapy (aOR, 1.44; 95\% Cl, 1.07; 1.94) (Table 3).

\section{Risk of overt gastrointestinal, occult gastrointestinal and non-gastrointestinal bleeding}

The risk of being hospitalized for overt gastrointestinal bleeding was increased after recent exposure to NSAIDs in both patients treated with anticoagulant therapy (aOR, 6.27; $95 \% \mathrm{Cl}, 2.24 ; 17.53)$ and in those treated with antiplatelet therapy $(\mathrm{aOR}, 1.81 ; 95 \% \mathrm{Cl}, 1.21 ; 2.72)$, compared to NSAID exposure during the control windows (Table 3). However, we did not observe an increased risk in hospitalizations for occult gastrointestinal bleeding.

The risk of non-gastrointestinal bleeding was increased in case of co-exposure to anticoagulants and NSAIDs during the hazard window $(\mathrm{aOR}, 2.72 ; 95 \% \mathrm{Cl}, 1.23 ; 6.04)$ compared to co-exposure during the control windows. The characteristics of patients hospitalized for non-gastrointestinal bleeding and their exposure to antithrombotic drugs were similar to those hospitalized for gastrointestinal bleeding (Tables S4 and S3, respectively). They were mainly men over 70. More than half of the patients in the anticoagulant group (55.2\%) were hospitalized for post-procedural bleeding or anemia caused by bleeding (Table S5). The main reasons for hospitalization in the antiplatelet group were postprocedural bleeding, $(29.5 \%)$, urinary bleeding $(18.4 \%)$, anemia caused by bleeding $(17 \%)$ and 
respiratory bleeding (17\%) (Table S5). The median hospital stay was 4.5 days (IQR [3; 9]) in the anticoagulant group and 8 days (IQR [4; 14]) in the antiplatelet group. Up to $11 \%$ of patients died during hospitalization in the anticoagulant group $(n=4)$ and $5 \%$ in the antiplatelet group $(n=14)$. The median time from NSAID dispensation to hospitalization in patients exposed to this drug during the hazard window was 7 days (IQR $[3 ; 10.75])$ in patients exposed to anticoagulant therapy, and 8 days (IQR [5; 12]) in patients exposed to antiplatelet therapy (Table S4).

Regardless of location, the association between severe bleeding and co-exposure to NSAIDs and anticoagulants (aOR, 2.53; 95\% Cl, 1.38; 4.63), or antiplatelet agents $(\mathrm{aOR}, 1.30 ; 95 \% \mathrm{Cl}, 1.06 ; 1.60)$ during the hazard window was still significant compared to that during the control windows (Table 3).

\section{Sensitivity analyses}

When the duration of the hazard and control windows was reduced, only patients exposed to antiplatelet agents had a significant increased risk of bleeding with 12-days and 7-days windows (Table 4). The risk of gastrointestinal bleeding was still significant, and higher when the persistence criterion (continuous exposure to antithrombotics) was reduced to fifteen days and seven days.

\section{Negative control using paracetamol exposure}

The risk of gastrointestinal bleeding after exposure to paracetamol was not significant in patients exposed to anticoagulants (aOR, 1.04; $95 \% \mathrm{Cl}, 0.82 ; 1.32)$ but was slightly increased in patients exposed to antiplatelets $(\mathrm{aOR}, 1.14 ; 95 \% \mathrm{Cl}, 1.01 ; 1.29)$ (Table 5). The risk of non-gastrointestinal bleeding increased significantly in patients with anticoagulants and paracetamol co-exposure (aOR, 1.25; 95\% $\mathrm{Cl}, 1.02 ; 1.54)$, but less so than with NSAID co-exposure (aOR, $2.72 ; 95 \% \mathrm{Cl}, 1.23 ; 6.04$, Tables 3 and 5$)$. The risk of non-gastrointestinal bleeding increased significantly in patients with antiplatelets and paracetamol co-exposure (aOR, 1.42; 95\% Cl, 1.26; 1.59) (Table 5). 


\section{Discussion}

The concomitant use of antithrombotics and NSAIDs is not recommended because the interaction of these drugs could have significant clinical consequences. In this study, an increased risk of gastrointestinal bleeding after exposure to NSAIDs was observed in patients receiving antithrombotic therapy. This risk seemed to be higher in patients exposed to anticoagulants than in those receiving antiplatelet agents. An increased risk was also observed in non-gastrointestinal bleeding following NSAID use in patients exposed to anticoagulants. The median age was over 65 whatever the type of bleeding.

Simultaneous exposure to NSAIDs and antithrombotic drugs is common. Indeed, $1.5 \%$ of the French population had simultaneous exposure to NSAIDs and antiplatelet drugs and $0.24 \%$ to NSAIDs and oral anticoagulants in $2016^{4}$. Thus, physicians should take this into consideration when prescribing these combinations. Previous studies have reported an increased risk of bleeding in patients in the same age group exposed to NSAIDs during antithrombotic therapy ${ }^{10,11,17-19}$. Although none of them used a casecrossover design (most were case-control studies), they report an increased risk of gastrointestinal bleeding consistent with our findings: from $1.81(95 \% \mathrm{Cl}, 1.35 ; 2.43)$ to $4.60(95 \% \mathrm{Cl}, 2.77 ; 7.64)$ for coexposure to anticoagulant therapy and NSAIDs ${ }^{11,17,18}$, and a 3.6 increase in the risk of hemorrhagic ulcers $(95 \% \mathrm{Cl}, 1.19 ; 10.81)$ in case of co-exposure to aspirin at antiplatelet doses and NSAIDs ${ }^{19}$. In our study, more than two thirds of the patients had dispensation of at least one gastric protector (PPI or $\mathrm{H} 2$ antagonists) during the study period (66.7\% in patients exposed to anticoagulants and $71.2 \%$ in those exposed to antiplatelet agents). This use of gastric protectors probably reduced the risk of ulcers and gastrointestinal bleeding ${ }^{20}$.

We also assessed the association between NSAID use and occult gastrointestinal bleeding, which has not been evaluated in previous studies. Because the main causes of iron deficiency anemia are occult gastrointestinal bleeding and heavy menstruation, we analyzed iron deficiency anemia in men of all ages and women over the age of 50 . No increased risk of occult gastrointestinal bleeding was identified 
probably because we only evaluated acute NSAID use 15 days prior to hospitalization, which would correspond more to acute bleeding than to chronic bleeding episodes such as occult gastrointestinal bleeding.

The biological mechanisms underlying these interactions are different depending on the antithrombotic agent. The pharmacological properties of NSAIDs are related to the inhibition of cyclooxygenase enzymes COX-1 and COX-2, which normally promote the conversion of arachidonic acid to prostaglandins or thromboxanes ${ }^{21,22}$. The risk of a pharmacokinetic interaction following coexposure to NSAIDs and anticoagulants is known, resulting in an increase in International Normalized Ratio (INR) ${ }^{23-25}$ or bleeding time ${ }^{26}$. The ulcerogenic risk and the antiplatelet effect of NSAIDs is a result of the inhibition of the cyclooxygenase COX-1 enzyme. Low-dose aspirin has antiplatelet aggregation properties through irreversible inhibition of the cyclooxygenase COX-1 enzyme, resulting in a potential pharmacodynamic interaction with NSAIDs. The other antiplatelet agents studied inhibit the adenosine diphosphate (ADP) receptor, and further studies are needed to clarify the mechanisms related to the potential interactions with NSAIDs ${ }^{27}$. We could not study Coxibs and non-selective NSAIDs separately because the number of patients was too limited. However, numerous studies have already shown an increased risk of bleeding following co-exposure to Coxib and antithrombotics ${ }^{10,21,28}$. Paracetamol was used as a negative control because its indications are similar to those of NSAIDs. Our mainly non-significant results, are consistent with the debate about the risk of bleeding following coexposure to antithrombotics and paracetamol ${ }^{29-31}$. Thus, although a NSAID-related indication bias cannot be completely excluded, our results suggest that paracetamol is safer to NSAIDs in patients exposed to antithrombotics.

The main strength of this study is the use of real-life data, with a representative nationwide database including about $1 \%$ of the French population. The case-crossover design could be used to assess the short-term change in the risk of an acute outcome associated with transient exposure with adjustment for time-invariant confounding factors ${ }^{8}$. We also used multiple control windows to increase the power 
of the study and the accuracy confidence interval estimates ${ }^{32}$. This methodology can be used for other drug-drug interactions in which one substance is used on a long-term basis and another one is administered for a short period. The ICD-10 codes related to severe bleeding were mainly selected from published studies and were reviewed by a group of experts ${ }^{10,11}$. Finally, sensitivity analyses were performed to confirm the robustness of the results. With a more restrictive definition of continuous exposure to antithrombotic drugs, the risks of gastrointestinal bleeding were similar to the estimates from the main analysis. When shorter exposure windows were used, the results were mainly nonsignificant, probably because of the lower number of patients included. However, the estimated aORs remained similar to those in the main analysis.

This study has several limitations, mainly related to the type of data. First, only dispensation of reimbursed drugs were available to assess drug consumption, excluding over-the-counter NSAIDs. Moreover, NSAIDs may have been purchased, but not used, by the patient. However, both these biases would tend to lower the association between NSAIDs and the risk of bleeding and cannot explain our results. Duration of treatment was not considered when determining NSAID exposure. Only patients with a dispensing date within the hazard or control windows were defined as exposed. Thus, there is a risk of misclassifying exposure and, again, underestimating the OR. The unidirectional case-crossover design requires the absence of time trend in the prevalence of drug exposure. Although the prevalence of exposure to this drug-drug interaction increased between 2006 and $2016^{4}$, the effect of this time trend bias may be negligible as the study period for each patient was short. Continuous exposure to antithrombotic therapy was defined by repeated antithrombotic dispensation to determine persistence. A dose-response relationship could not be investigated, and we do not know whether the antithrombotic drugs were taken for preventive or curative purposes. In addition, in this observational study, we could not control NSAID-related indication bias. However, paracetamol was used as negative control to estimate the impact of this potential bias. 


\section{Conclusion}

NSAID use increased the risk of gastrointestinal and non-gastrointestinal bleeding in patients treated with anticoagulants, and to a lesser extent the risk of gastrointestinal bleeding in patients treated with antiplatelet agents. The prescription of NSAIDs should be avoided in patients taking antithrombotics. Since several NSAIDs are available without a prescription, patients exposed to antithrombotic therapy should also be educated about the risks associated with this drug-drug interaction. 
Figures

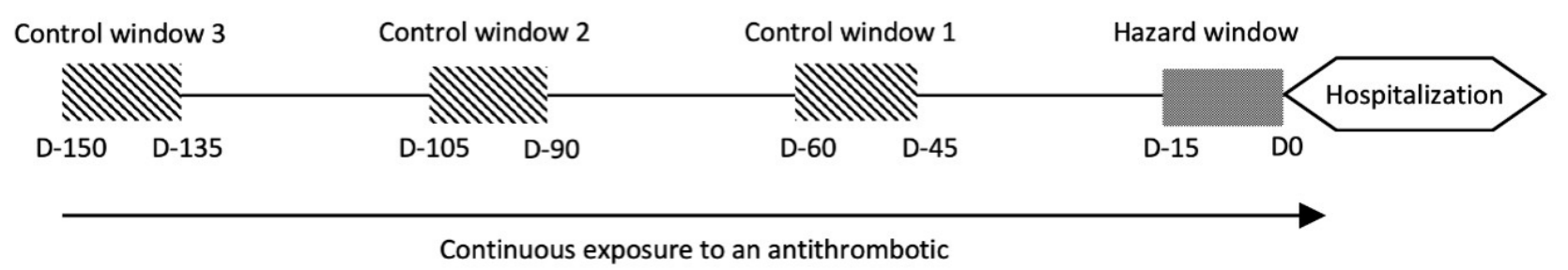

Figure 1. Case-crossover study design. Exposure to nonsteroidal anti-inflammatory drugs were compared during the hazard window and the three control windows. 


\section{Anticoagulants}

Patients in the EGB exposed

simultaneously to anticoagulants and NSAIDs between 2009 and 2017

$$
\mathrm{N}=8272
$$

including

Patients hospitalized for gastrointestinal bleeding during or within 15 days after the end of the concomitant exposure $\mathrm{N}=74$

Absolute risk analysis

Patients hospitalized for gastrointestinal bleeding with continuous exposure to anticoagulants at least 150 days before the hospitalization and exposed to NSAID at least once during the 150-day period

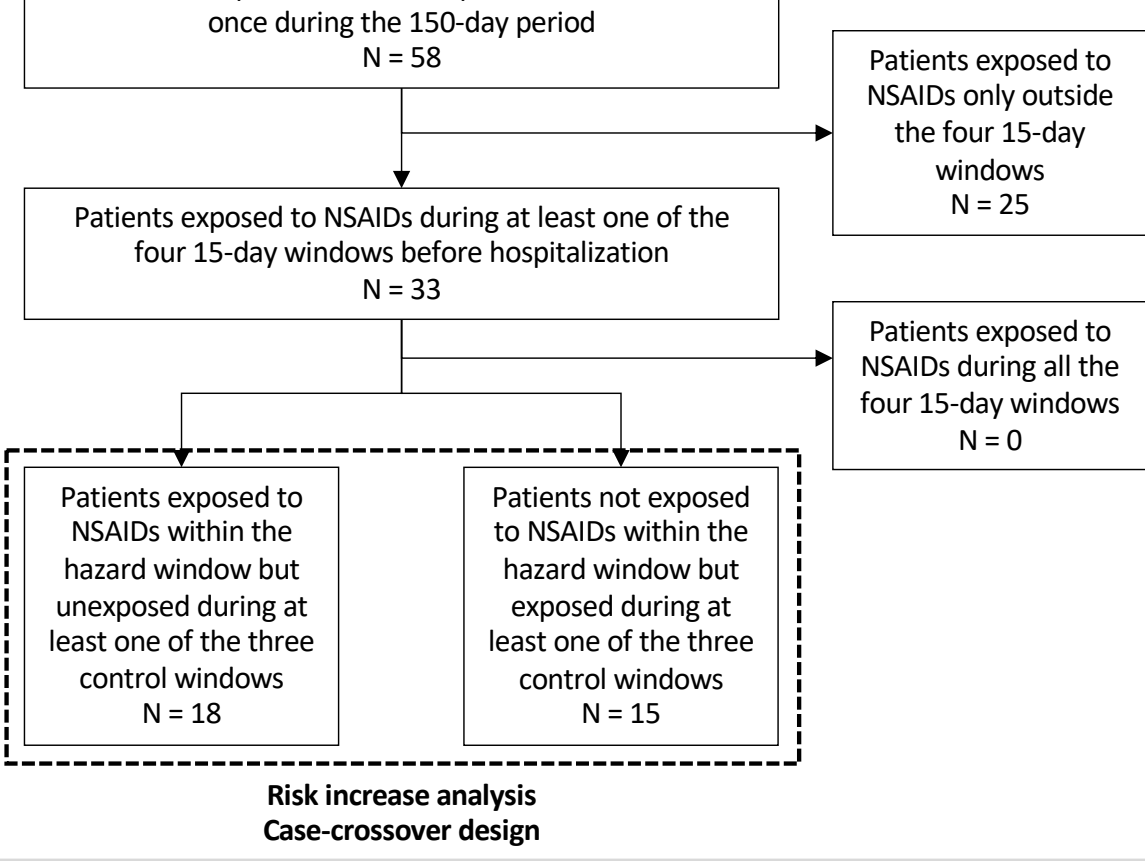

Antiplatelet agents

Patients in the EGB exposed simultaneously to antiplatelet agents and NSAIDs between 2009 and 2017

$$
\mathrm{N}=37718
$$

including

Patients hospitalized for gastrointestinal bleeding during or within 15 days after the end of the concomitant exposure

$$
\mathrm{N}=296
$$

\begin{tabular}{|c|c|c|}
\hline \multicolumn{2}{|c|}{$\begin{array}{l}\text { Patients hospitalized for gastrointestinal bleeding with } \\
\text { continuous exposure to antiplatelet agents at least } 150 \\
\text { days before the hospitalization and exposed to NSAID at } \\
\text { least once during the } 150 \text {-day period } \\
\qquad N=421\end{array}$} & \multirow{2}{*}{$\begin{array}{l}\text { Patients exposed to } \\
\text { NSAIDs only outside } \\
\text { the four 15-day } \\
\text { windows } \\
\mathrm{N}=168\end{array}$} \\
\hline & & \\
\hline \multicolumn{2}{|c|}{$\begin{array}{l}\text { Patients exposed to NSAIDs during at least one of the } \\
\text { four 15-day windows before hospitalization } \\
\qquad N=253\end{array}$} & \\
\hline & 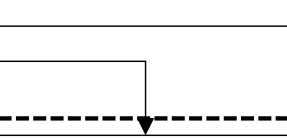 & $\begin{array}{l}\text { NSAIDs during all the } \\
\text { four 15-day windows } \\
\qquad \mathrm{N}=3\end{array}$ \\
\hline $\begin{array}{l}\text { Patients exposed to } \\
\text { NSAIDs within the } \\
\text { hazard window but } \\
\text { unexposed during at } \\
\text { least one of the three } \\
\text { control windows } \\
\mathrm{N}=104\end{array}$ & $\begin{array}{l}\text { Patients not exposed } \\
\text { to NSAIDs within the } \\
\text { hazard window but } \\
\text { exposed during at } \\
\text { least one of the three } \\
\text { control windows } \\
N=146\end{array}$ & \\
\hline
\end{tabular}

Absolute risk analysis

Figure 2. Patient selection for the absolute risk analysis and for the case-crossover analysis. 


\section{Tables}

Table 1. Characteristics, drug exposure and type of NSAIDs dispensed during the hazard window, in patients hospitalized for gastrointestinal bleeding after being continuously exposed to antithrombotics and with discordant NSAID exposure across the hazard and control windows.

\begin{tabular}{|c|c|c|}
\hline \multirow{3}{*}{ Characteristics No (\%) } & \multicolumn{2}{|c|}{ Overt or occult gastrointestinal bleeding } \\
\hline & \multicolumn{2}{|c|}{ Antithrombotic Group } \\
\hline & $\begin{array}{l}\text { Anticoagulant } \\
\qquad(\mathrm{N}=\mathbf{3 3})\end{array}$ & $\begin{array}{l}\text { Antiplatelet agent } \\
\qquad(\mathrm{N}=\mathbf{2 5 0})\end{array}$ \\
\hline Women & $14(42 \%)$ & $119(48 \%)$ \\
\hline Age (years), median [IQR] & $74[69 ; 79]$ & $78[68 ; 84]$ \\
\hline Duration of hospitalization (days), median [IQR] & $7[3 ; 10]$ & $7[4 ; 13]$ \\
\hline Death at hospital & $1(3 \%)$ & $9(3.6 \%)$ \\
\hline \multicolumn{3}{|l|}{$\begin{array}{l}\text { At least one dispensation within one of the } \\
\text { control and hazard windows }\end{array}$} \\
\hline $\mathrm{PPI}$ or $\mathrm{H} 2$ antagonists & 22 (66.7\%) & $178(71.2 \%)$ \\
\hline Systemic or inhaled corticosteroids & $7(21.2 \%)$ & $30(12 \%)$ \\
\hline Anticoagulant & - & $8(3.2 \%)$ \\
\hline Antiplatelet agent & $9(27.3 \%)$ & - \\
\hline $\begin{array}{l}\text { Dispensation of NSAIDs during the hazard } \\
\text { window }\end{array}$ & $18(55 \%)$ & $104(42 \%)$ \\
\hline Non-selective NSAIDs & $17(94 \%)$ & $96(92.3 \%)$ \\
\hline Coxib & $1(6 \%)$ & $8(7.7 \%)$ \\
\hline $\begin{array}{l}\text { Delay between NSAID dispensation and } \\
\text { hospital admission (days), median [IQR] }\end{array}$ & $6.5[2.5 ; 11.8]$ & $8[4 ; 11]$ \\
\hline
\end{tabular}

NSAIDs: nonsteroidal anti-inflammatory drugs, IQR: interquartile range, PPI: proton pomp inhibitor 
Table 2. Hospitalizations for gastrointestinal bleeding in patients included in the main analysis.

\begin{tabular}{|c|c|c|c|}
\hline & Events No (\%) & $\begin{array}{l}\text { Anticoagulant } \\
(\mathrm{N}=33)\end{array}$ & $\begin{array}{l}\text { Antiplatelet agent } \\
(\mathrm{N}=\mathbf{2 5 0})\end{array}$ \\
\hline \multirow{3}{*}{$\begin{array}{l}\text { Overt } \\
\text { gastrointestinal } \\
\text { bleeding }\end{array}$} & $\begin{array}{llr}\text { Anal/rectal hemorrhage, } & \text { melena, } \\
\text { hematemesis or } & \text { unspecified } \\
\text { gastrointestinal hemorrhage } & \end{array}$ & $20(61 \%)$ & $120(48 \%)$ \\
\hline & Hemorrhagic ulcer or gastritis & $3(9 \%)$ & $21(8 \%)$ \\
\hline & $\begin{array}{l}\text { Anal/rectal hemorrhage, melena, } \\
\text { hematemesis or unspecified } \\
\text { gastrointestinal hemorrhage } \\
\text { + Hemorrhagic ulcer or gastritis }\end{array}$ & $1(3 \%)$ & $7(3 \%)$ \\
\hline $\begin{array}{c}\text { Occult } \\
\text { gastrointestinal } \\
\text { bleeding }\end{array}$ & $\begin{array}{l}\text { Iron deficiency anemia in men of all ages } \\
\text { and women over } 50 \text { years of age }\end{array}$ & $9(27 \%)$ & $102(41 \%)$ \\
\hline
\end{tabular}


Table 3. Risk of hospitalisation for severe bleeding after NSAID exposure in patients exposed to continuous antithrombotic treatment in case-crossover study.

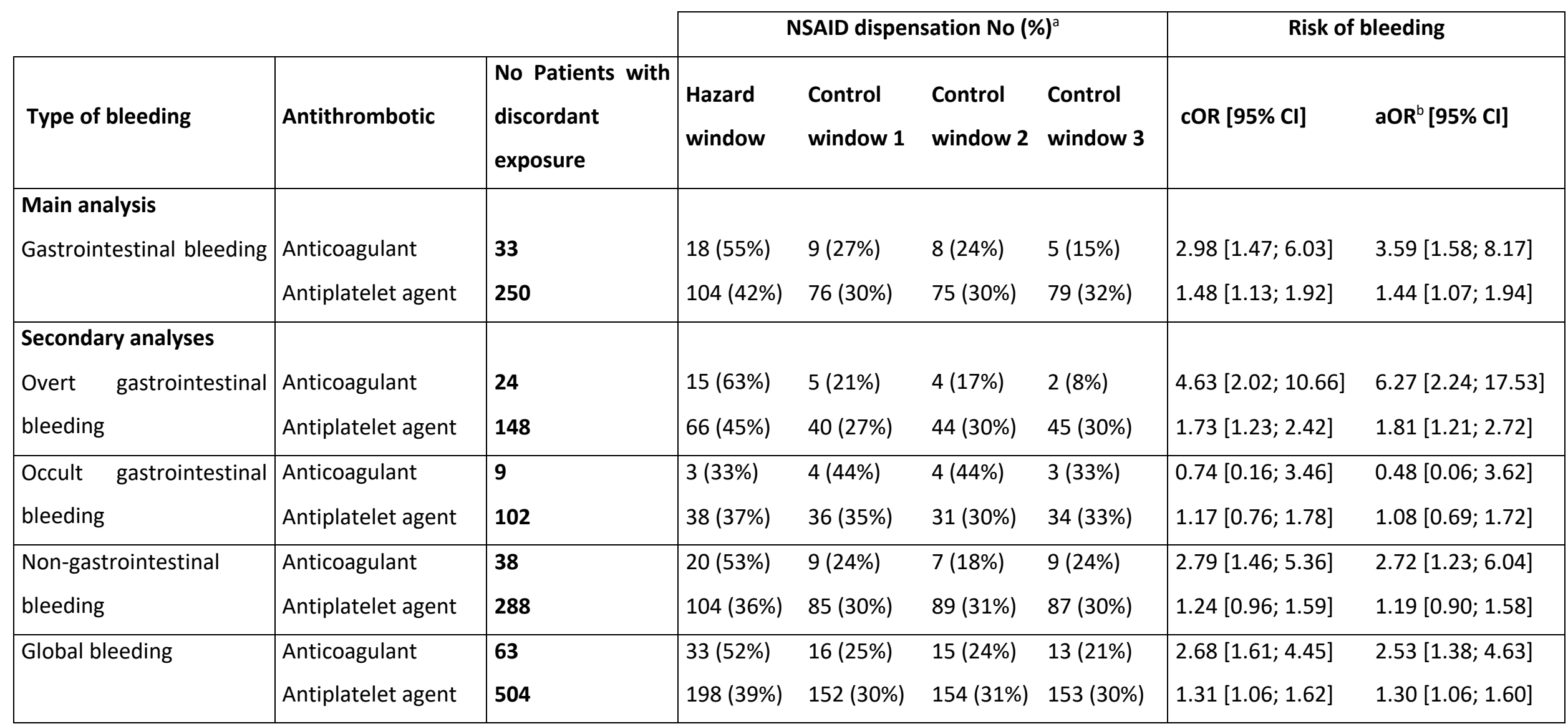

NSAID: nonsteroidal anti-inflammatory drug, cOR: crude odds ratio, aOR: adjusted odds ratio, Cl: confidence interval

${ }^{a}$ Frequency of exposure to NSAIDs in the patients included in the analysis because of discordant NSAID exposure.

${ }^{\mathrm{b}}$ Adjusted for the concomitant use of PPI/H2 antagonists, systemic or inhaled corticosteroids, anticoagulant in patients exposed to antiplatelet therapy and antiplatelet therapy in patients exposed to anticoagulant therapy. 
Table 4. Sensitivity analyses: risk of hospitalisation for gastrointestinal bleeding after exposure to NSAIDs in patients exposed to continuous antithrombotic treatment in a case-crossover study with different window durations and persistence criterion.

\begin{tabular}{|c|c|c|c|c|c|}
\hline \multicolumn{2}{|l|}{ Gastrointestinal bleeding } & \multicolumn{2}{|r|}{ Anticoagulant } & \multicolumn{2}{|c|}{ Antiplatelet agent } \\
\hline Parameter & Number of days & $N$ & $\mathrm{aOR}^{\mathrm{a}}[95 \% \mathrm{Cl}]$ & $N$ & $\mathrm{aOR}^{\mathrm{a}}[95 \% \mathrm{Cl}]$ \\
\hline & 12 & 31 & $2.22[0.99 ; 4.98]$ & 219 & $1.39[1.01 ; 1.91]$ \\
\hline Duration of hazard and & 10 & 28 & $1.45[0.59 ; 3.56]$ & 200 & $1.29[0.92 ; 1.80]$ \\
\hline control windows (days) & 7 & 22 & $1.66[0.57 ; 4.85]$ & 142 & $1.50[1.06 ; 2.13]$ \\
\hline $\begin{array}{l}\text { Duration of grace period } \\
\text { used in persistence } \\
\text { criterion (days) }\end{array}$ & 15 & 25 & $4.28[1.58 ; 11.59]$ & $\begin{array}{l}189 \\
109\end{array}$ & $\begin{array}{l}1.68[1.20 ; 2.37] \\
1.69[1.09 ; 2.61]\end{array}$ \\
\hline
\end{tabular}

aOR: adjusted odds ratio, $\mathrm{Cl}$ : confidence interval

${ }^{\text {a }}$ Adjusted for the concomitant use of $\mathrm{PPI} / \mathrm{H} 2$ antagonists, systemic or inhaled corticosteroids, anticoagulants in patients exposed to antiplatelet therapy and antiplatelet therapy in patients exposed to anticoagulant therapy. 
Table 5. Risk of hospitalisation for severe bleeding after paracetamol exposure in patients exposed to continuous antithrombotic treatment in case-crossover study.

\begin{tabular}{|c|c|c|c|c|c|c|c|c|}
\hline \multirow[b]{2}{*}{ Type of bleeding } & \multirow[b]{2}{*}{ Antithrombotic } & \multirow[b]{2}{*}{$\begin{array}{l}\text { No Patients } \\
\text { with discordant } \\
\text { exposure }\end{array}$} & \multicolumn{4}{|c|}{ Paracetamol dispensation No (\%) ${ }^{a}$} & \multicolumn{2}{|c|}{ Risk of bleeding } \\
\hline & & & $\begin{array}{l}\text { Hazard } \\
\text { window }\end{array}$ & $\begin{array}{l}\text { Control } \\
\text { window } 1\end{array}$ & $\begin{array}{l}\text { Control } \\
\text { window } 2\end{array}$ & $\begin{array}{l}\text { Control } \\
\text { window } 3\end{array}$ & COR $[95 \% \mathrm{Cl}]$ & $\mathrm{aOR}^{\mathrm{b}}[95 \% \mathrm{Cl}]$ \\
\hline $\begin{array}{l}\text { Main analysis } \\
\text { Gastrointestinal bleeding }\end{array}$ & $\begin{array}{l}\text { Anticoagulant } \\
\text { Antiplatelet agent }\end{array}$ & $\begin{array}{l}406 \\
1394\end{array}$ & $\begin{array}{l}178(44 \%) \\
605(43 \%)\end{array}$ & $\begin{array}{l}165(41 \%) \\
534(38 \%)\end{array}$ & $\begin{array}{l}164(40 \%) \\
553(40 \%)\end{array}$ & $\begin{array}{l}163(40 \%) \\
515(37 \%)\end{array}$ & $\begin{array}{l}1.13[0.92 ; 1.40] \\
1.20[1.07 ; 1.34]\end{array}$ & $\begin{array}{l}1.04[0.82 ; 1.32] \\
1.14[1.01 ; 1.29]\end{array}$ \\
\hline $\begin{array}{l}\text { Secondary analyses } \\
\text { Overt gastrointestinal } \\
\text { bleeding }\end{array}$ & $\begin{array}{l}\text { Anticoagulant } \\
\text { Antiplatelet agent }\end{array}$ & $\begin{array}{l}207 \\
771\end{array}$ & $\begin{array}{l}97(47 \%) \\
341(44 \%)\end{array}$ & $\begin{array}{l}78(38 \%) \\
281(36 \%)\end{array}$ & $\begin{array}{l}84(41 \%) \\
296(38 \%)\end{array}$ & $\begin{array}{l}79(38 \%) \\
274(36 \%)\end{array}$ & $\begin{array}{l}1.33[0.99 ; 1.79] \\
1.30[1.12 ; 1.51]\end{array}$ & $\begin{array}{l}1.19[0.85 ; 1.67] \\
1.19[1.00 ; 1.40]\end{array}$ \\
\hline $\begin{array}{l}\text { Occult gastrointestinal } \\
\text { bleeding }\end{array}$ & $\begin{array}{l}\text { Anticoagulant } \\
\text { Antiplatelet agent }\end{array}$ & $\begin{array}{l}199 \\
623\end{array}$ & $\begin{array}{l}81(41 \%) \\
264(42 \%)\end{array}$ & $\begin{array}{l}87(44 \%) \\
253(41 \%)\end{array}$ & $\begin{array}{l}80(40 \%) \\
257(41 \%)\end{array}$ & $\begin{array}{l}84(42 \%) \\
241(39 \%)\end{array}$ & $\begin{array}{l}0.95[0.71 ; 1.29] \\
1.08[0.91 ; 1.28]\end{array}$ & $\begin{array}{l}0.90[0.64 ; 1.27] \\
1.09[0.90 ; 1.32]\end{array}$ \\
\hline $\begin{array}{l}\text { Non-gastrointestinal } \\
\text { bleeding }\end{array}$ & $\begin{array}{l}\text { Anticoagulant } \\
\text { Antiplatelet agent }\end{array}$ & $\begin{array}{l}495 \\
1550\end{array}$ & $\begin{array}{l}215(43 \%) \\
719(46 \%)\end{array}$ & $\begin{array}{l}193(39 \%) \\
586(38 \%)\end{array}$ & $\begin{array}{l}184(37 \%) \\
561(36 \%)\end{array}$ & $\begin{array}{l}170(34 \%) \\
561(36 \%)\end{array}$ & $\begin{array}{l}1.26[1.05 ; 1.53] \\
1.40[1.26 ; 1.56]\end{array}$ & $\begin{array}{l}1.25[1.02 ; 1.54] \\
1.42[1.26 ; 1.59]\end{array}$ \\
\hline Global bleeding & $\begin{array}{l}\text { Anticoagulant } \\
\text { Antiplatelet agent }\end{array}$ & $\begin{array}{l}792 \\
2643\end{array}$ & $\begin{array}{l}349(44 \%) \\
1190(45 \%)\end{array}$ & $\begin{array}{l}311(39 \%) \\
1005(38 \%)\end{array}$ & $\begin{array}{l}304(38 \%) \\
1009(38 \%)\end{array}$ & $\begin{array}{l}297(38 \%) \\
968(37 \%)\end{array}$ & $\begin{array}{l}1.22[1.05 ; 1.42] \\
1.30[1.20 ; 1.41]\end{array}$ & $\begin{array}{l}1.16[0.98 ; 1.37] \\
1.27[1.16 ; 1.39]\end{array}$ \\
\hline
\end{tabular}

cOR: crude odds ratio, aOR: adjusted odds ratio, $\mathrm{Cl}$ : confidence interval

${ }^{\text {a }}$ Frequency of exposure to paracetamol in the patients included in the analysis because of discordant paracetamol exposure.

${ }^{b}$ Adjusted for concomitant use of NSAIDs, PPI/H2 antagonists, systemic or inhaled corticosteroids, anticoagulant therapy in patients exposed to antiplatelet therapy and antiplatelet therapy in patients exposed to anticoagulant therapy.

22 


\section{References}

1. Snaith A, Pugh L, Simpson CR, McLay JS. The Potential for Interaction between Warfarin and Coprescribed Medication: A Retrospective Study in Primary Care. Am J Cardiovasc Drugs. 2008;8(3):207-212.

2. Ilomäki J, Helin-Salmivaara A, Huupponen R, Rikala M, Kirkpatrick CM, Korhonen MJ. Analgesic use before and after oral anticoagulant initiation-a population-based study in Finland. Eur J Clin Pharmacol. 2015;71(6):723-732.

3. Flipo R-M. Are the NSAIDs able to compromising the cardio-preventive efficacy of aspirin? Presse Medicale Paris Fr 1983. 2006;35(9 Spec No 1):1S53-60.

4. Souty C, Launay $T$, Steichen $O$, et al. Use of the French healthcare insurance database to estimate the prevalence of exposure to potential drug-drug interactions. Eur J Clin Pharmacol. 2020.

5. French National Agency for Medicines and Health Products Safety. Thesaurus des interactions médicamenteuses. $\quad$ https://ansm.sante.fr/Dossiers/Interactions-medicamenteuses/Interactionsmedicamenteuses/(offset)/0.

6. Food and Drug Administration. Concomitant Use of Ibuprofen and Aspirin: Potential for Attenuation of the AntiPlatelet Effect of Aspirin. September 2006. https://www.fda.gov/media/76636/download.

7. Tuppin P, Rudant J, Constantinou P, et al. Value of a national administrative database to guide public decisions: From the système national d'information interrégimes de l'Assurance Maladie (SNIIRAM) to the système national des données de santé (SNDS) in France. Rev Epidemiol Sante Publique. 2017;65 Suppl 4:S149-S167.

8. Maclure M. The Case-Crossover Design: A Method for Studying Transient Effects on the Risk of Acute Events. Am J Epidemiol. 1991;133(2):144-153.

9. Hertz FB, Jensen A, Knudsen JD, et al. Does macrolide use confer risk of out-of-hospital cardiac arrest compared with penicillin V? A Danish national case-crossover and case-time-control study. BMJ Open. 2018;8(2):e019997. 
10. Schjerning Olsen A-M, Gislason GH, McGettigan P, et al. Association of NSAID Use With Risk of Bleeding and Cardiovascular Events in Patients Receiving Antithrombotic Therapy After Myocardial Infarction. JAMA. 2015;313(8):805.

11. Battistella M. Risk of Upper Gastrointestinal Hemorrhage in Warfarin Users Treated With Nonselective NSAIDs or COX-2 Inhibitors. Arch Intern Med. 2005;165(2):189.

12. Lamberts M, Olesen JB, Ruwald MH, et al. Bleeding After Initiation of Multiple Antithrombotic Drugs, Including Triple Therapy, in Atrial Fibrillation Patients Following Myocardial Infarction and Coronary Intervention: A Nationwide Cohort Study. Circulation. 2012;126(10):1185-1193.

13. Patrono C, Baigent C, Hirsh J, Roth G. Antiplatelet drugs: American College of Chest Physicians Evidence-Based Clinical Practice Guidelines (8th Edition). Chest. 2008;133(6 Suppl):199S-233S.

14. Vilcu A-M, Sabatte L, Blanchon T, et al. Association Between Acute Gastroenteritis and Continuous Use of Proton Pump Inhibitors During Winter Periods of Highest Circulation of Enteric Viruses. JAMA Netw Open. 2019;2(11):e1916205.

15. WHO. WHOCC - DDD - Definition and general considerations. https://www.whocc.no/ddd/definition_and_general_considera/.

16. Bykov K, Mittleman MA, Glynn RJ, Schneeweiss S, Gagne JJ. The Case-Crossover Design for DrugDrug Interactions: Considerations for Implementation. Epidemiology. 2019;30(2):204-211.

17. Delaney JA, Opatrny L, Brophy JM, Suissa S. Drug drug interactions between antithrombotic medications and the risk of gastrointestinal bleeding. Can Med Assoc J. 2007;177(4):347-351.

18. Kent AP, Brueckmann M, Fraessdorf M, et al. Concomitant Oral Anticoagulant and Nonsteroidal AntiInflammatory Drug Therapy in Patients With Atrial Fibrillation. J Am Coll Cardiol. 2018;72(3):255-267.

19. Kawasaki K, Kurahara K, Yanai S, Kochi S, Fuchigami T, Matsumoto T. Low-Dose Aspirin and Nonsteroidal Anti-inflammatory Drugs Increase the Risk of Bleeding in Patients with Gastroduodenal Ulcer. Dig Dis Sci. 2015;60(4):1010-1015.

20. Bhatt DL, Scheiman J, Abraham NS, et al. ACCF/ACG/AHA 2008 expert consensus document on 
reducing the gastrointestinal risks of antiplatelet therapy and NSAID use: a report of the American College of Cardiology Foundation Task Force on Clinical Expert Consensus Documents. Circulation. 2008;118(18):18941909.

21. Villa Zapata L, Hansten PD, Panic J, et al. Risk of Bleeding with Exposure to Warfarin and Nonsteroidal Anti-Inflammatory Drugs: A Systematic Review and Meta-Analysis. Thromb Haemost. 2020;120(07):10661074.

22. Matsui H, Shimokawa O, Kaneko T, Nagano Y, Rai K, Hyodo I. The pathophysiology of non-steroidal anti-inflammatory drug (NSAID)-induced mucosal injuries in stomach and small intestine. J Clin Biochem Nutr. 2011;48(2):107-111.

23. Choi KH, Kim AJ, Son IJ, et al. Risk Factors of Drug Interaction between Warfarin and Nonsteroidal Anti-Inflammatory Drugs in Practical Setting. J Korean Med Sci. 2010;25(3):337.

24. Schaefer MG, Plowman BK, Morreale AP, Egan M. Interaction of rofecoxib and celecoxib with warfarin. Am J Health Syst Pharm. 2003;60(13):1319-1323.

25. Van Dijk K, Plat A, Van Dijk A, et al. Potential interaction between acenocoumarol and diclofenac, naproxen and ibuprofen and role of CYP2C9 genotype. Thromb Haemost. 2004;91(01):95-101.

26. Kubitza D, Becka M, Mueck W, Zuehlsdorf M. Rivaroxaban (BAY 59-7939) ? an oral, direct Factor Xa inhibitor ? has no clinically relevant interaction with naproxen. Br J Clin Pharmacol. 2007;63(4):469-476.

27. Nam YH, Brensinger CM, Bilker WB, et al. Nonsteroidal anti-inflammatory drug choice and adverse outcomes in clopidogrel users: A retrospective cohort study. Leong C, ed. PLOS ONE. 2018;13(3):e0193800. 28. Hauta-Aho M, Tirkkonen $\mathrm{T}$, Vahlberg $\mathrm{T}$, Laine $\mathrm{K}$. The effect of drug interactions on bleeding risk associated with warfarin therapy in hospitalized patients. Ann Med. 2009;41(8):619-628.

29. Mahe I, Bertrand N, Drouet L, et al. Paracetamol: a haemorrhagic risk factor in patients on warfarin. Br J Clin Pharmacol. 2005;59(3):371-374.

30. Hylek EM, Heiman H, Skates SJ, Sheehan MA, Singer DE. Acetaminophen and Other Risk Factors for Excessive Warfarin Anticoagulation. JAMA. 1998;279(9):657. 
31. Jick H. Effects of aspirin and acetaminophen in gastrointestinal hemorrhage. Results from the Boston Collaborative Drug Surveillance Program. Arch Intern Med. 1981;141(3):316-321.

32. Mittleman MA, Maclure M, Robins JM. Control Sampling Strategies for Case-Crossover Studies: An Assessment of Relative Efficiency. Am J Epidemiol. 1995;142(1):91-98. 